\title{
A systematic review of pediatric cognitive rehabilitation in the elementary and middle school systems
}

\author{
Dorothy R. Shaw \\ Baltimore City Public Schools, 502 Epsom Road, Baltimore, MD 21286, USA \\ E-mail:DRShaw@bcps.k12.md.us
}

\begin{abstract}
.
BACKGROUND: Cognitive Rehabilitation Therapy (CRT) is efficacious in remediating cognitive deficits, and has been demonstrated to be effective in a school setting.

OBJECTIVE: The purpose of this paper is to review the literature on pediatric CRT as it relates to successful re-integration of TBI survivors into the school system and community.

METHODS: This systematic review of the literature suggests that social re-integration strategies which incorporate problemsolving, reasoning, self-awareness, and positive social skills within a developmental framework are the most effective techniques for Pediatric CRT.

RESULTS: Children and adolescents with cognitive impairments benefit from a holistic approach to rehabilitation which incorporates developmental, social, and emotional considerations, as well as, cognitive rehabilitation techniques.

CONCLUSIONS: This systematic review identifies several avenues for effective therapeutic interventions for school aged TBI survivors. Many are supported by laboratory based efficacy studies. Future research should investigate optimal ages for particular treatments, as well as, the effectiveness of treatments across different social settings.
\end{abstract}

Keywords: Pediatric, cognitive rehabilitation, systematic review, elementary school, middle school

\section{Introduction}

A number of published studies have documented the efficacy of cognitive rehabilitation therapy (CRT) for remediating cognitive deficits in clinical as well as school settings (Hanten et al., 2000; Khan et al., 2003; Laatsch et al., 2007; Slomine \& Locascio 2009; Cook et al., 2014; Rath et al., 2011; Marcantuono \& Prigatano, 2008; and Shaw, 2013). Pediatric traumatic brain injury is known to impact executive functions, such as attention and working memory, as well as children's ability to accurately estimate their performance and ability to learn. Children with brain injuries (TBI survivors) tend to overestimate their abilities and learning. This overestimation is attributed to their failure to use metacognitive strate- gies to reduce short-term memory deficits (Hanten et al., 2000). While memory deficits frequently predispose placement in special school programs; relatively few children demonstrate improved memory functioning with recovery (Van Heugten et al., 2006). Memory deficits are often permanent following moderate to severe TBI, which contribute to weakened learning and performance (Nybo et al., 2005). Shaw (2013) asserted that CRT was effective for improving memory, planning, reasoning, and problem-solving in the school setting. This systematic review investigates the effectiveness of anecdotal treatments and remediation strategies and their generalization to a broader range of settings to which children and adolescents must re-adjust following brain injury. 


\section{Systematic review of effective CRT treatments}

A summary of studies of pediatric CRT effectiveness within the last decade is presented in Table 1. This is not a complete list; selection preference favored recent studies and patient populations that fell within an age range generally associated with childhood, early adolescence, the elementary, or the middle school educational systems.

Most studies investigated executive dysfunction, and deficits in this area were found to negatively impact children's quality of life and everyday academic functioning. In general, the literature suggests that children experience decreased quality of life across cognitive, physical, and psychosocial domains (Cook et al., 2014; Sesma et al., 2008). Otero et al. (2014) found that different types of interventions were most appropriate at different stages of development. Nadebaum et al. (2007) reported that the younger a child is at injury, the more profound the effect of the injury upon development. Because children are developing skills at the time of the injury, that development is interrupted. Nadebaum (2007) reported that the more severe the injury, the longer executive functioning deficits remained. Long-term executive functioning deficits were not associated with mild or moderate injuries (Nadebaum et al., 2007). However, injury severity is inversely related to successful school re-integration (Arroyos-Jurado et al., 2000).

\section{Cognitive interventions}

Many of the interventions in Table 1 focused upon executive skills and problem-solving. These studies indicate that brain injured individuals benefit more from learning reasoning strategies rather than from learning strategies designed to improve rote memory. Learning to reason helps the TBI survivor comprehend abstract meanings and solve novel problems that he or she may encounter during the day. Individuals who learn only memory strategies do not necessarily show significant improvements in these areas (Cook, 2014). Improving reasoning skills also transfers to an injured child's academic performance (Sesma et al., 2008). Because children spend a majority of their time in school, the academic setting therefore provides the most opportunities for rehabilitation. Slomine and Locascio (2009) recommended that interventions for cognitive deficits need to be integrated into children's classroom experience. However, Hawley et al. (2004) pointed out that there is often a lack of communication between schools and caregivers regarding the extent of a TBI survivor's injury and his/her prognosis, which limits successful re-integration (Hawley et al., 2004). Caregivers and school personnel need to collaborate concerning the child's abilities and limitations, in order to develop an appropriate academic program.

\section{Social interventions}

Despite a seeming wealth of excellent suggestions regarding direction for pediatric CRT, it remains difficult to facilitate childhood participation in the social and academic community. Social skills and adaptive behavior may require sustained retraining (Khan, Baguley, Cameron, 2003). Marcantuono and Prigatano (2008) investigated social skills training using a pediatric holistic neuropsychological rehabilitation program. These authors suggested that measures of improved social relationships, academic performance, and parent and teacher stress were the best indices of success (Marcantuono \& Prigatano, 2008). The holistic model included therapeutic activities ranging from teaching introspection and self-monitoring, self-awareness, and self-advocacy skills for remediating executive functions, academic skills, social skills, and activities of daily living. Depending on the age of the injured child, group counseling or play therapy was effective. Generally, the study demonstrated that a holistic rehabilitation program improved children's ability to cope, and increased their self-awareness and cognition. It also improved their general social integration.

Rath et al. (2011) investigated remediating functional problem-solving deficits by teaching students to monitor negative internal dialogues. Injured students were taught to identify alternative ways of thinking, and replace their dysfunctional self-talk with a more positive perspective. Rath et al. (2011) demonstrated that injured individuals underestimated their abilities to solve problems, and were generally threatened by their thinking difficulties. Interventions were more effective when the students were taught to make positive self-statements (Rath et al., 2011).

Perna et al. (2004) asserted that group-based techniques may be effective for teaching new executive skills as applied to social settings. These authors concluded that homogenous groups allow injured individuals to identify with others with the same 
Table 1

Studies predictive of successful recovery after pediatric brain injury

\begin{tabular}{|c|c|c|c|c|}
\hline Study & $\mathrm{N}$ & Age & Predictors & Area studied \\
\hline Agnihotri et al. (2012) & 2 & Adolescents & Childhood Brain Disorder & Social Skills \\
\hline Anderson et al. (2002) & 124 & $3-12$ & Age at time of injury & Intellectual Functioning \\
\hline $\begin{array}{l}\text { Arroyos-Jurado et al. } \\
\quad(2000)\end{array}$ & 43 & $6-14$ & $\begin{array}{l}\text { Premorbid functioning } \\
\text { Severity Age at injury }\end{array}$ & $\begin{array}{l}\text { Reading and Spelling } \\
\text { achievement Adaptive } \\
\text { functioning }\end{array}$ \\
\hline Cook et al. (2014) & 20 & $12-20$ & Chronic recovery stages & Cognitive Training \\
\hline Hanton et al. (2000) & 9 & Children & $\begin{array}{l}\text { Frontal lobe pathology } \\
\text { Injury severity }\end{array}$ & Executive functions \\
\hline Hawley et al. (2004) & 67 & School-age & Intelligence Verbal Recall & Special Education needs \\
\hline Laatsch et al. (2007) & 366 & Children and Youth & $\begin{array}{l}\text { Cognitive Rehabilitation } \\
\text { Speech Therapy } \\
\text { Language Therapy } \\
\text { Behavior Therapy }\end{array}$ & $\begin{array}{l}\text { Treatment } \\
\text { recommendations }\end{array}$ \\
\hline Muscara et al. (2008) & 36 & $8-12$ & Severity & Executive \\
\hline $\begin{array}{l}\text { Marcantuono and } \\
\text { Prigatano (2008) }\end{array}$ & & Children & Acquired Brain Injury & $\begin{array}{l}\text { Holistic } \\
\quad \text { Neurorehabilitation }\end{array}$ \\
\hline Nedabaum et al. (2007) & 54 & $1-7$ & Severity & $\begin{array}{l}\text { Executive Family } \\
\text { Functioning }\end{array}$ \\
\hline Nybo et al. (2005) & 22 & Preschool & $\begin{array}{l}\text { Intelligence Verbal Recall } \\
\text { Marital Status }\end{array}$ & Vocational Outcome \\
\hline Otero et al. (2014) & & Children & $\begin{array}{l}\text { Age Disorder } \\
\text { Comorbidity Outcomes }\end{array}$ & Executive \\
\hline Prasad et al. (2002) & 60 & LT6 & $\begin{array}{l}\text { \# of Brain Lesions } \\
\text { Abnormal Pupilary } \\
\text { Inflicted Injury }\end{array}$ & Glasgow Coma Scale \\
\hline Perna et al. (2004) & & & & Group Therapy \\
\hline Sesma et al., 2008 & 330 & $5-15$ & $\begin{array}{l}\text { Injury Severity Pre-injury } \\
\text { learning and behavior } \\
\text { problems Family } \\
\text { Resources Family } \\
\text { Functioning }\end{array}$ & Executive Functioning \\
\hline Slomine et al. (2002) & 68 & $7-15$ & $\begin{array}{l}\text { Number of Lesions Age } \\
\text { at Injury Verbal IQ }\end{array}$ & Executive \\
\hline $\begin{array}{l}\text { Slomine and Locascio } \\
\text { (2009) }\end{array}$ & Adults Children & Cognitive deficits & $\begin{array}{l}\text { Cognitive Rehabilitation } \\
\text { Speech/Language } \\
\text { Family Education }\end{array}$ & \\
\hline Van Heugten et al. (2006) & 31 & Adolescents Children & Lower Education & $\begin{array}{l}\text { Intellectual Functioning } \\
\text { Family Functioning }\end{array}$ \\
\hline
\end{tabular}

problems, and to receive feedback from each other with safe interpersonal conversation. Group interventions allowed opportunities for interpersonal practice when learning to solve a problem or to perform a particular task (Perna et al., 2004).

Laatsch et al. (2007) reported that school teachers who had been trained in metacognitive strategies including attention and memory significantly improved their verbal memories. The learned strategies thus transfer to injured students, as well as, family members (Laastsch et al., 2007). Whittingham (2014) recommended incorporating mindfulness into interventions. Whittingham defined "mindfulness" as “... deliberate nonjudgmental attention to moment-to-moment experience" (p. 704), and recommended that mindfulness should be taught through exercises which decrease the use of language.

\section{Community reintegration}

The effectiveness of cognitive rehabilitation is ultimately tested within the community. Rath et al. (2011) suggested that increasing confidence and problem-solving ability was the key to effective community reintegration. The authors' problem-oriented framework focused upon the assumptions and expectations survivors have about themselves and how they believe they are perceived by others. The hallmarks of this therapy included acceptance of their injury and self-reliance on developing individual strategies 
for accomplishing tasks. Effective therapy should provide opportunities to reason through every-day practical dilemmas on the playground, in school, or in shopping centers, or restaurants. In this type of treatment, the world is the therapeutic venue (Brunzwick, 1952). Injured children demonstrate their skills with activities such as finding items in a store, resolving disagreements with family and friends, identifying solutions to everyday dilemmas, and developing appropriate behavioral scripts for handling crises.

Agnihotri et al. (2012) suggested that children's difficulties with social skills stem from social isolation. The authors recommended using arts-based interventions to increase self-confidence and improve social participation. With training, children were better able to articulate their feelings, reflect upon them with increased abstract thinking, and participate socially (Agnihotri et al., 2012).

\section{First steps towards standardized treatment}

Several suggestions for effective pediatric and school based interventions can be derived from this systematic review. Treatments that help the student to organize will be most effective. For example, providing a planner which contains the student's daily schedule, names of people with whom he or she interacts, and necessary locations-addresses-phone numbers will usually be helpful. Designating space in the planner for "Things To Do" and "Things To Return", and creating a system for checking off when things are completed are especially useful. The planner may also include a list of functional mnemonics which can be used to cue recall of important factual information. Simply having the planner available will facilitate meta memory, i.e., "remembering to remember".

The literature also suggests that effective therapy is developmentally appropriate. Therapies designed for elementary school-age children should be more behavior-oriented while middle and high-school age children are more capable of introspection. Middle and high-schoolers may benefit from reasoning strategies (e.g., assessing cost and benefits), and be encouraged to draw their own conclusions. Creative arts are appropriate at any age.

Training to recognize and to regulate emotional states is especially important. Exercises such as drawing faces that express different emotions or selecting pictures from magazines that illustrate emotions and making them into collages ("feelings collage") can help injured children to recognize and respond appropriately to others' moods. Training children to articulate their feelings and to predict how their moods affect others may also be helpful. Having the child watch age appropriate television programming with the sound turned off and trying to guess the emotion of the actors from facial expression and body language builds non-verbal communication skills. Having children generate lists of words each day that express their feeling and self-concept then turning these into "word clouds" (www.abcya.com/word_clouds.htm) will highlight those words that the children typically associate with their emotional status.

Effective treatment emphasizes real-life social situations which the children will likely encounter. Examples of this type of treatment include fostering partner activities which require cooperation with another child in order to be successful or interactions that involve identifying "Who, Where, When, What Happened, What Happened Next, How It Ends". Older students may benefit from teaching relationship-building skills to distinguish appropriate behaviors to use with adults and peers (e.g., www.Socialskillscentral.com).

Finally, it will also be necessary to assess treatment effectiveness with a pre- and post-treatment assessment, using standardized instruments such as the Behavior Assessment System for Children - Third Edition (BASC-3; Reynolds \& Kamphaus, 2015) or the Achenbach System of Empirically Based Assessment (ASEBA; Achenback \& Rescorla, 2001), or the Brief Rating Inventory of Executive Functions (Roth, Isquith, and Gioia, 2005) along with performance based assessments such as classroom grades.

\section{Conclusions}

These suggestions for effective treatments of children with traumatic brain injuries derive from a systematic review of pediatric and school based CRT. The combination of these literature based therapies along with the author's experiential suggestions provide a basis for effective treatments of children and young adults with traumatic brain injuries. This paper was designed to broaden the research on the efficacy of cognitive rehabilitation of executive and social skills, and particularly to suggest effective interventions for children and adolescents with brain injuries in school and in the community. This is a first step toward the goal of aggregating effective anecdotal 
treatments into a standardized treatment battery for individuals with TBI's and other brain-based disabilities. Future research should investigate optimal ages for particular treatments, as well as, the effectiveness of treatments across different social settings.

\section{Conflict of interest}

The author has no conflict of interest to report.

\section{References}

Agnihotri, S., Bray, J., Colantonio, A., Polatajko, H., Cameron, D., Wiseman-Hakes, C., Rumney P., \& Keightley, M. (2012). Two case study evaluations of an arts-based social skills intervention for adolescents with childhood brain disorder. Developmental NeuroRehabilitation, 15(4), 284-297.

Arroyos-Jurado, E., Paulsen, J. S., Merrell, K. W., Lindgren, S. D., \& Max, J. E. (2000). Traumatic Brain injury in schoolage children academic and social outcome. Journal of School Pschology, 38(6), 571-587.

Brunswik, E. (1952). The conceptual framework of psychology. Chicago: University of Chicago Press.

Cook, L. G., Chapman, S. B., Elliott, A. C., Evenson, N. N., \& Vinton, K. (2014). Cognitive gains from gist reasoning training in adolescents with chronic-stage traumatic brain injury. Frontiers in Neurology, 5, 1-9.

Hanten, G., Bartha, M., \& Levin, H. S. (2000). Metacognition following pediatric traumatic brain Injury: A preliminary study. Developmental Neuropsychology, 18(3), 383-398.

Hawley, C. A., Ward, A. B., Magnay, A. R., \& Mychalkiw, W. (2004). Return to school after brain Injury. Archives of Disease in Childhood, 89, 136-142.

Khan, F., Baguley, I. J., \& Cameron, I. D. (2003). Rehabilitation after traumatic brain injury. Medical Journal of Australia, 178(6), 290-295.

Laatsch, L., Harrington, D., Hotz, G., Marcantuono, J., Mozzoni, M. P., Walsh, V., \& Hersey, K. P. (2007). An evidence-based review of cognitive and behavioral rehabilitation treatment studies in children with acquired brain injury. Journal of Head Trauma Rehabilitation, 22(4), 248-256.

Marcantuono, J. T. \& Prigatano, G. P. (2008). A holistic brain injury rehabilitation program for school-age children. NeuroRehabilitation, 23, 457-466.

Nadebaum, C., Anderson, V., \& Catroppa, C. (2007). Executive function outcomes following Traumatic brain injury in young children: A five year follow-up. Developmental Neuropsychology, 32(2), 703-728.

Nybo, T., Sainio, M., \& Muller, K. (2005). Middle age cognition and vocational outcome of childhood brain injury. Acta Neurologica Scandinavica, 112, 338-342.

Otero, T. M., Barker, L. A., \& Naglieri, J. A. (2014) Executive functioning treatment and intervention in schools. Applied Neuropsychology Child, 3(3), 205-214.

Perna, R. B., Bubier, J., Oken, M., Snyder, R., \& Rousselle, A. (2004). Brain Injury Rehabilitation: Activity-based and thematic group treatment. The Journal of Cognitive Rehabilitation (pp. 20-24).

Rath, J. F., Hradil, A. L., Litke, D. R., \& Diller, L. (2011). Clinical applications of problem-solving research in neuropsychological rehabilitation: Addressing the subjective experience of ognitive deficits in outpatients with acquired brain injury. Rehabilitation Psychology, 56(4), 320-328.

Roth, R. M., Isquith, P. K. \& Gioia, G. A. (2005) Behavior rating inventory of executive function, Psychological Assessment Resources.

Sesma, H. W., Slomine, B. S., Ding, R., McCarthy, M. L., (2008). Executive functioning in the first year after pediatric traumatic brain injury. CHAT Study Group. Pediatrics, 121, 1686-1695.

Shaw, D. R. (2013). Pediatric cognitive rehabilitation: Effective treatments in a school-based environment. NeuroRehabilitation, 34(1), 23-28.

Slomine, B. \& Locascio, G. (2009). Cognitive rehabilitation for children with acquired brain Injury. Developmental Disabilities Research Reviews, 15(2), 133-143.

Van Heugten, C. M., Hendriksen, J., Rasquin, S., Dijcks, B., Jaeken, D. \& Vles, J. H. S. (2006). Long-term neuropsychological performance in a cohort of children and adolescents after Severe paediatric treatment brain injury. Brain Injury, 20(9), 895-903.

Whittingham, K. (2014). Parents of children with disabilities, mindfulness and acceptance: A review and a call for research. Mindfulness, 5, 704-709. 